\title{
Hegzagonal Bor Nitrür Takviyeli ZA40 Alaşımının Mekanik ve Aşınma Özelliklerinin Araştırılması
}

\author{
Emre Deniz YALÇIN ${ }^{1 *}$, Aykut ÇANAKÇI ${ }^{2}$
}

\section{$\ddot{\mathbf{O} z}$}

Bu çalışmada ZA40 çinko-alüminyum alaşımına ağırlıkça \% 0-\%1-\%2-\%3 ve \%4 oranında hegzagonal yapılı bor nitrür (h-BN) katılarak toz metalürjisi tekniği ve sıcak pres yöntemi kullanılarak numuneler üretilmiştir. Bu karışımlar gezegen tipi yüksek enerjili bilyeli öğütücüde 3 saat öğütme süresinde oda sıcaklığında ve $\% 60$ bağıl nem altında $400 \mathrm{rpm}$ devirde öğütülmüştür. Öğütülen tozlardan $495^{\circ} \mathrm{C}^{\prime}$ de $700 \mathrm{MPa}$ basınç altında, sıcak presleme tekniği kullanılarak kompozitler üretilmiştir. Aşınma deneyleri ball on disk tekniği kullanılarak kuru sürtünme ortamında $5 \mathrm{~N}$ ve $10 \mathrm{~N}$ yükler altında gerçekleştirilmiştir. Aşınma deneylerinde numunelerin ağırlık kayıpları hesaplanmıştır. Numunelerin morfolojileri, içyapı görüntüleri ve aşınma yüzeylerinin incelenmesi (SEM) Taramalı elektron mikroskobu ve X-Ray difraksiyonu kullanılarak incelenmiştir. Ortaya çıkan sonuçlara göre h-BN takviyeli ZA40 ile matris malzemesi arasında mekanik, fiziksel ve tribolojik farklılıkların olduğu açıkça görülmüştür. Özellikle artan h-BN takviyesinde aşınma değerlerinin belirgin ölçüde azalma gösterdiği gözlenmiştir.

Anahtar Kelimeler: ZA40, h-BN, Aşınma, Toz Metalürjisi.

\section{Investigation of Mechanical and Wear Properties of Hexagonal Boron Nitride Reinforced ZA40 Alloy}

\begin{abstract}
In this study, samples were produced using powder metallurgy technique and hot press method by adding $0-\% 1-\% 2-3 \%$ and $4 \%$ hexagonal structured boron nitride (h-BN) to ZA40 zinc-aluminum alloy by weight. These mixtures were ground in a planetary type high-energy ball mill at $400 \mathrm{rpm}$ for 3 hours at room temperature and $60 \%$ relative humidity. Composite were produced from the ground powders under $700 \mathrm{MPa}$ pressure at $495^{\circ} \mathrm{C}$ by using hot pressing technique. Abrasion experiments were carried out under $5 \mathrm{~N}$ and $10 \mathrm{~N}$ loads in dry friction environment by using ball on disc technique. The weight losses of the samples were calculated in the wear tests. Morphology, internal structure images and examination of wear surfaces (SEM) of the samples were investigated using scanning electron microscopy and X-Ray diffraction. The results clearly showed that there are mechanical, physical and tribological differences between the h-BN reinforced ZA40 and the matrix material. It was observed that the wear values decreased significantly with increasing h-BN reinforcement.
\end{abstract} Keywords: ZA40, h-Boron Nitride, Wear, Powder Metallurgy.

\footnotetext{
${ }^{1}$ Karadeniz Teknik Üniversitesi, Abdullah Kanca Meslek Yüksekokulu, Trabzon, Türkiye, emredenizyalcin@ktu.edu.tr

${ }^{2}$ Karadeniz Teknik Üniversitesi, Mühendislik Fakültesi, Metalürji ve Malzeme Mühendisliği, Trabzon, Türkiye, aykut@ktu.edu.tr
}

${ }^{1}$ https://orcid.org/0000-0001-9691-1017 2 https://orcid.org/0000-0001-5244-6467 


\section{Giriş}

Çinko- Alüminyum (Zn-Al) alaşımları günümüzde pek çok mühendislik uygulamalarında başarılı bir şekilde kullanılmaktadır. Özellikle Zn-Al serisi alaşımlar; dayanıklılık, iyi ısı iletkenliği, iyi sinterlenebilme ve rijitlik gibi pek çok özelliklerinden ötürü birçok endüstriyel uygulamalarda alüminyum ve bronz alaşımlara göre daha çok tercih edilmektedir (Ranganath ve ark., 2001). Zn-Al alaşımları; dökme demir, pirinç ve alüminyum ile kıyaslandığında düşük ergime sıcaklığı ve düşük maliyette olması bununla birlikte daha üstün tribolojik etkiler ortaya koyması açısından oldukça önemli bir yere sahiptir (Smith, 1993).

Katı yağlayıcı olarak h-BN, grafit benzeri bir katmanlı yapıda olup seramik malzemeler grubuna dahildir. $\mathrm{Bu}$ nedenle mükemmel yağlayıcılık gibi tribolojik özelliklere sahiptir. Katı yağlayıcı olarak h-BN, yüksek sıcaklık, vakum ortamı ve sıvı yağlama maddeleri ve başka yağlayıcıların kullanılmasının mümkün olmadığı durumlarda, alternatif yağlayıcı olarak kullanılmıştır. Takviye elemanı olarak h-BN tozlarının kullanıldığı kompozitlerde, aşınma direnci gelişmiştir ( Hsu ve ark., 2016; Hsu ve ark., 2015).

Yapılan bir çalışmada; ZA27, ZA35 ve ZA40 alaşımlarına farklı oranlarda yttrium (Y) katarak mekanik özellikleri incelenip efektif sonuçlar elde edilmiştir. Özellikle \%4 Y takviyesi ile kompozitlerin uzama gerilmesi ve sertlik değerlerinde önemli artışların meydana geldiği görülmüştür( Li ve ark., 2015).

ZA27 matris içerisine ağırlıkça \%3, \%6 ve \%9 oranlarında $\mathrm{B}_{4} \mathrm{C}$ takviyesi yaparak oluşturulan kompozitlerin mikroyapısal ve mekanik özelliklerini incelenmesiyle ilgili yapılan bir çalışmanın sonucunda; artan $\mathrm{B}_{4} \mathrm{C}$ takviyesi ile numunelerin sertlik değerlerinde artış, kopma uzamasında azalma meydana geldiğini göstermiştir (Dama ve ark., 2017).

Son zamanlarda yapılan başka bir çalışmada ise ZA27 matris içerisine \%1,5 SiC, \%0,5 oranında grafit katarak ZA27/SiC/Gr hibrit kompozitlerin pin on disk aşınma cihazında kuru sürtünme ortamında 20-40 ve $60 \mathrm{~N}$ yükler altında aşınma davranışlarını ve mekanik özelliklerini incelenmiştir. Sonuçlara göre mikro sertlik ve kopma gerilmesi değerlerinde artış meydana gelmiştir. Ayrıca numunelerde aşınma sonrası oluşan ağırlık kayıpları hibrit kompozitlerde matris malzemesine göre daha az çıkmıştır (Kumar, 2018).

2021 yılında yapılan bir çalışmada toz metalürjisi tekniği kullanılarak üretilen ZA40-\%5 h-BN kompozitinin farklı yük ve farklı devir sayılarında sabit tutulan yolda farklı miktarlarda kütle kayıpları verdiği görülmüştür. Özellikle artan yük miktarı daha fazla aşınma kaybına neden olmuştur. Burada yükün etkisinin hıza oranla daha fazla olduğu söylenebilir. Her iki aşınma türü de abrasif aşınma olarak değerlendirilmektedir (Yalçın ve Çanakçı, 2021). 
ZA40/Nikel kompozitleri ilgili yapılan bir çalışmada, takviye miktarı ve dağılımı, matris ve takviye partikülleri arasındaki bağlar ile ara yüzey reaksiyonlarından başka aşınma özelliklerini etkileyen başlıca faktörlerden oldukları görülmüştür. Özellikle matris içerisinde bulunan sert partikül takviyeler kompozitin yük taşıma kapasitesini artırırken aynı zamanda matris ile takviye arasındaki bağlanma dayanımlarında düşüş görülmektedir (Yalçın ve Çanakçı, 2021).

\section{Materyal ve Metot}

ZA40 alaşım tozları matris, h-BN tozları ise takviye malzemesi olarak kullanılmıştır. ZA40 alaşımı İki-El Metal Tozları A.Ş firmasından temin edilerek kimyasal bileşimi Tablo 1'de gösterilmiştir. Takviye malzemesi h-BN ise Alfa Aesar firmasından temin edilmiştir. Ayrıca numunelerin takviye oranları ve kodlamaları Tablo 2'de belirtilmiştir. Takviye malzemesi ile ZA40 matris tozları (Retsch PM 200) markalı gezegen tipideki bilyalı öğütücüde 3 saat sürede argon atmosferinde $400 \mathrm{rpm}$ devirde karıştırılmıştır. Öğütme işleminde $10 \mathrm{~mm}$ çapında tungsten karbür bilyeler kullanılmış olup bilye: toz ağırlık oranı 5:1 olarak uygun görülmüştür. Toz karışımları 4140 çelik malzemeden imal edilmiş $30 \mathrm{~mm}$ genişliğinde kalıp içerisine yerleştirilip $700 \mathrm{MPa}$ ve $495{ }^{\circ} \mathrm{C}$ de 3 saat sicak preslenmeye (hot pres) tabi tutulmuştur. Sicak preslemeye geçilmeden önce numuneler $300 \mathrm{MPa}$ basınç altında, 1 dakika sürede soğuk ön preslemeye tabi tutulmuştur. Çinko stearat topaklanmayı önlemek için ağırlıkça \% 0,5 oranında kullanılmıştır. Üretilen numunelerin teorik yoğunlukları karışımlar kuralı uygulanarak belirlenmiştir. Deneysel yoğunluklarda Arşimet metodu uygulanmıştır. Numunelerin boyutları $\pm 0,01 \mathrm{~mm}$ hassasiyete kumpasla ölçüldükten sonra $\pm 0,01 \mathrm{mg}$. hassasiyette hassas terazide ölçülerek ölçümler yapılmıştır. Numunelerin sertlik ölçümleri 2,5 mm çapında batıcı uç kullanılarak 31,25 kgf yük altında Brinell sertlik ölçüm yöntemi ile 8 ölçüm yapılmış ve aritmetik ortalaması alınarak belirlenmiştir. Aşınma testleri için hazırlanan kompozitlerin yüzeyleri 400, 800, 1000, 1200, 1500 ve 2000 numaralı zımparalar ile zımparalanıp olabildiğince düz yüzey elde edilmiştir. Aşınma dayanım testlerinde ball on disk aşınma mekanizması kullanılmıştır. Aşındırıcı bilyeler $10 \mathrm{~mm}$ çapında olup H11 sıcak iş takım çeliğinden imal edilmiştir. Aşınma testleri 5 ve $10 \mathrm{~N}$ yük altında, 250rpm hızda ve 100 metre yol alınarak gerçekleştirilmiştir. Öğütülen kompozit tozlara ait morfolojiler ve içyapı analizleri ZEISS LS 10 marka taramalı elektron mikroskobu (SEM) kullanılarak incelenmiştir. Takviyelerin matris içerisinde dağılımı, porozite ve numunelerin arayüzey incelemeleri SEM ve XRD analizleri ile detaylı bir şekilde yapılmıştır. SEM'de aşınma deneyleri sonrasında aşınma çeşidi, yüzey durumu ve aşınma yüzeyindeki tahribatlar incelenmiştir. XRD analizleri, $40 \mathrm{kV}$ ve $30 \mathrm{~mA}$ koşullarında ve Cuka (1,54059 Ao ) radyasyonu altında gerçekleştirilmiş olup çekimler $10-80^{\circ}$ ve $2 \theta$ arasında yapılmıştır. 
Tablo 1. ZA40 alaşımının kimyasal dağılımı (ağırlıkça \%).

\begin{tabular}{ccc}
\hline $\mathrm{Al}$ & $\mathrm{Cu}$ & $\mathrm{Zn}$ \\
\hline 43,29 & 1,92 & 54,79 \\
\hline
\end{tabular}

Tablo 2. Numunelerin kodlanması ve takviye oranları

\begin{tabular}{crc}
\hline Numune Kod & ZA40 (\%) & h-BN (\%) \\
\hline ZA40 & 100 & 0 \\
ZBN-1 & 99 & 1 \\
ZBN-2 & 98 & 2 \\
ZBN-3 & 97 & 3 \\
ZBN-4 & 96 & 4 \\
\hline
\end{tabular}

\section{Bulgular ve Tartışma}

\subsection{Mikroyapı}

ZA40/h-BN kompozitlerde h-BN tozlarının ZA40 matris tozların içine homojen olarak dağıtılması ve aynı zamanda yeterince gömülmesini sağlamak için 3 saatlik bir öğütme süresini belirlenmiştir. Şekil 1 ve şekil 2'de 1.00 K.X büyütmede hegzagonal yapıdaki bor nitrür (h-BN), ZA40 matris içerisinde gömülü olarak açık şekilde görülmektedir.

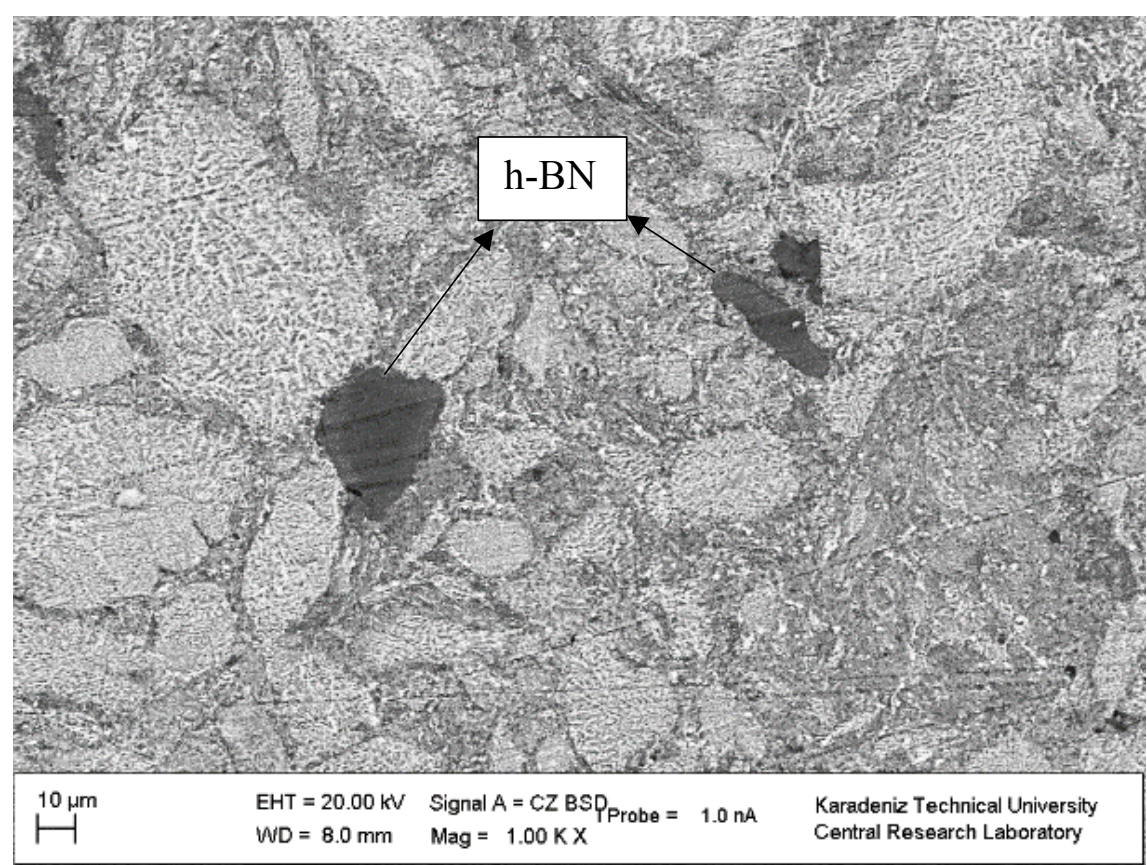

Şekil 1. ZBN-4 kompozitin SEM görüntüsü 
EDS analizi yapılan ZBN4 numunesinin Şekil 3'de bakıldığında Zn oranı \%23 iken Al oranı \%68 olduğu görülmektedir. Al içeriği daha zengin olduğundan bu fazın $\alpha$ fazı olduğu düşünülmektedir.

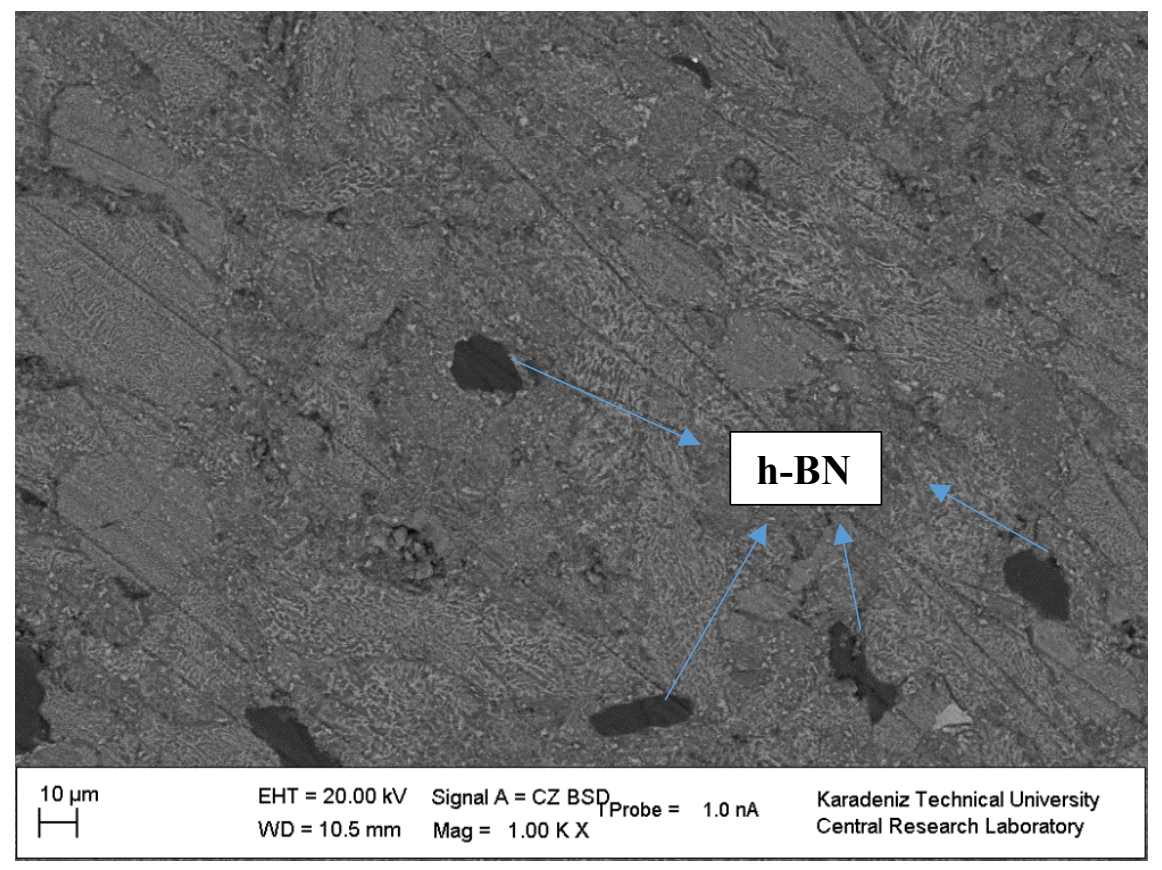

Şekil 2. ZBN-4 kompozitin SEM görüntüsü 1.00 K.X

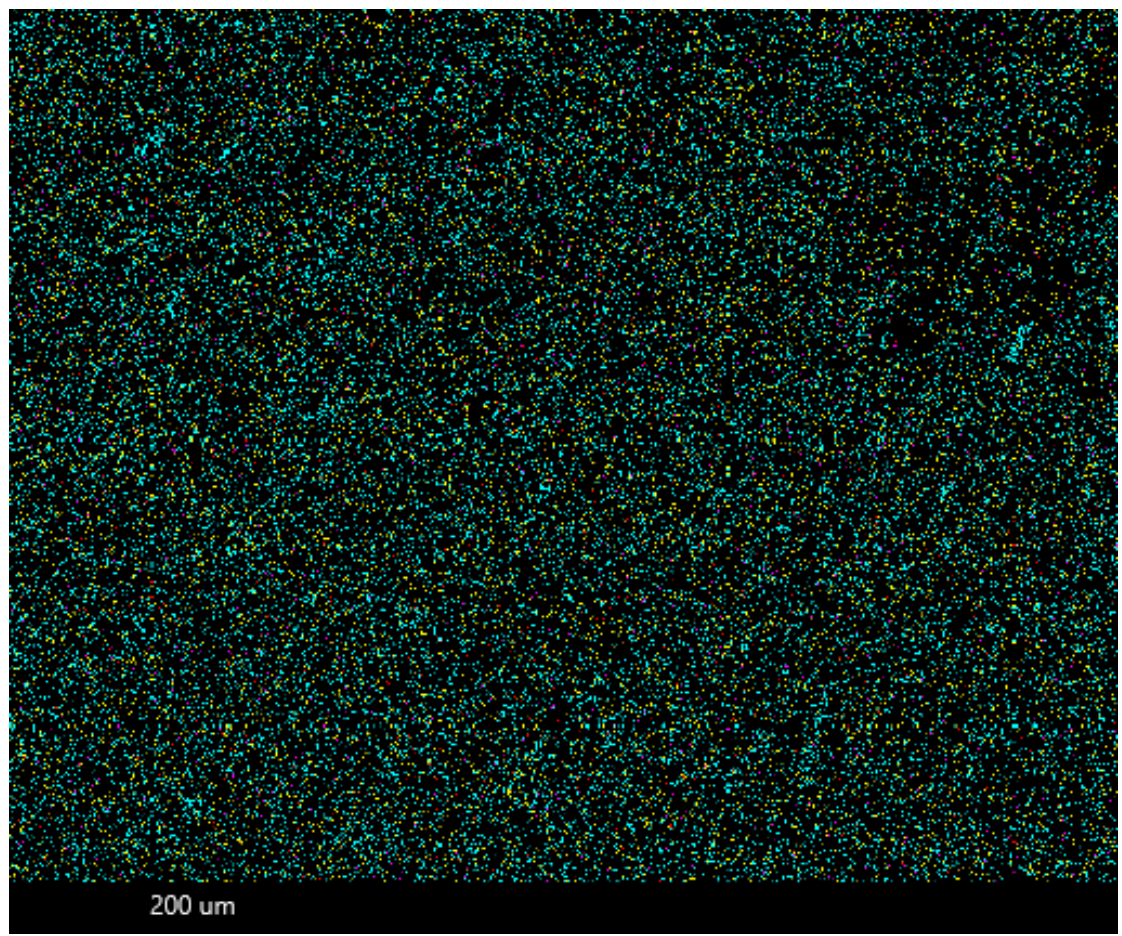




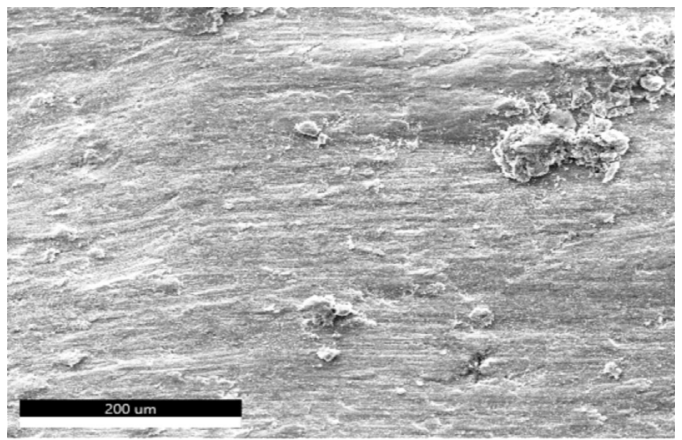

\section{$1 \%$ B K \\ $3 \%$ N K \\ $68 \%$ AIK \\ $2 \% \mathrm{SnL}$ \\ $1 \%$ FoK \\ $2 \%$ cuk \\ 23\% Znk}

Şekil. 3. ZBN-4 kompozit numunenin SEM -EDS analizi

Zn-Al alaşımlı kompozit malzemelerde yüksek bir performans elde etmek için takviye partiküllerinin matris içerisinde homojen dağılımın sağlanması ve bununla beraber takviye partikülleri ile matris arasında iyi bir arayüzey bağının oluşturulması gereklidir (Yalçın, 2018). Şekil 3.'de ZA40/h-BN kompozitlerine ait olan SEM-EDS analizi element dağılımları verilmiştir. Bu içyapılara göre, gri, yeşil, mavi ve sarı bölgeler sırasıyla B,N, Al ve Zn'nin elemental dağılımını göstermektedir.

h-BN parçacık kümelenmesinde bir artış, h-BN parçacıklarının aglomerasyonunda bir artışa sebep olmaktadır. Özetle, ZA40 matrisindeki h-BN parçacıklarının dağılımı homojen değildir. Daha fazla h-BN parçacık kümesinin, ZA40/h-BN kompozitlerinin mekanik özelliklerini, aşınmasını ve tribolojik özeliklerini olumsuz etkilediği sonucuna varılabilir.

\subsection{XRD Analizi}

Şekil 4'de gösterilen XRD grafikleri incelendiği zaman ZA40 alaşım matrisinin ve takviyeli ZBN-4 kompozitinin kırınım zirveleri açıkça görülmektedir. Zn ve Al pikleri daha belirgin pik yüksekliğinde görülürken h-BN pikleri 28 ve $42^{\circ}$ aralıklarda daha düşük kırınım olarak gözükmektedir. Özellikle h-BN takviye oranı ile berber Zn ve Al piklerinde düşüş göze çarpmaktadır. Takviye oranlarındaki değişim ile beraber bu piklerde de değişim görülebilir. h-BN oranının artırılması h-BN piklerini artırabilir. 

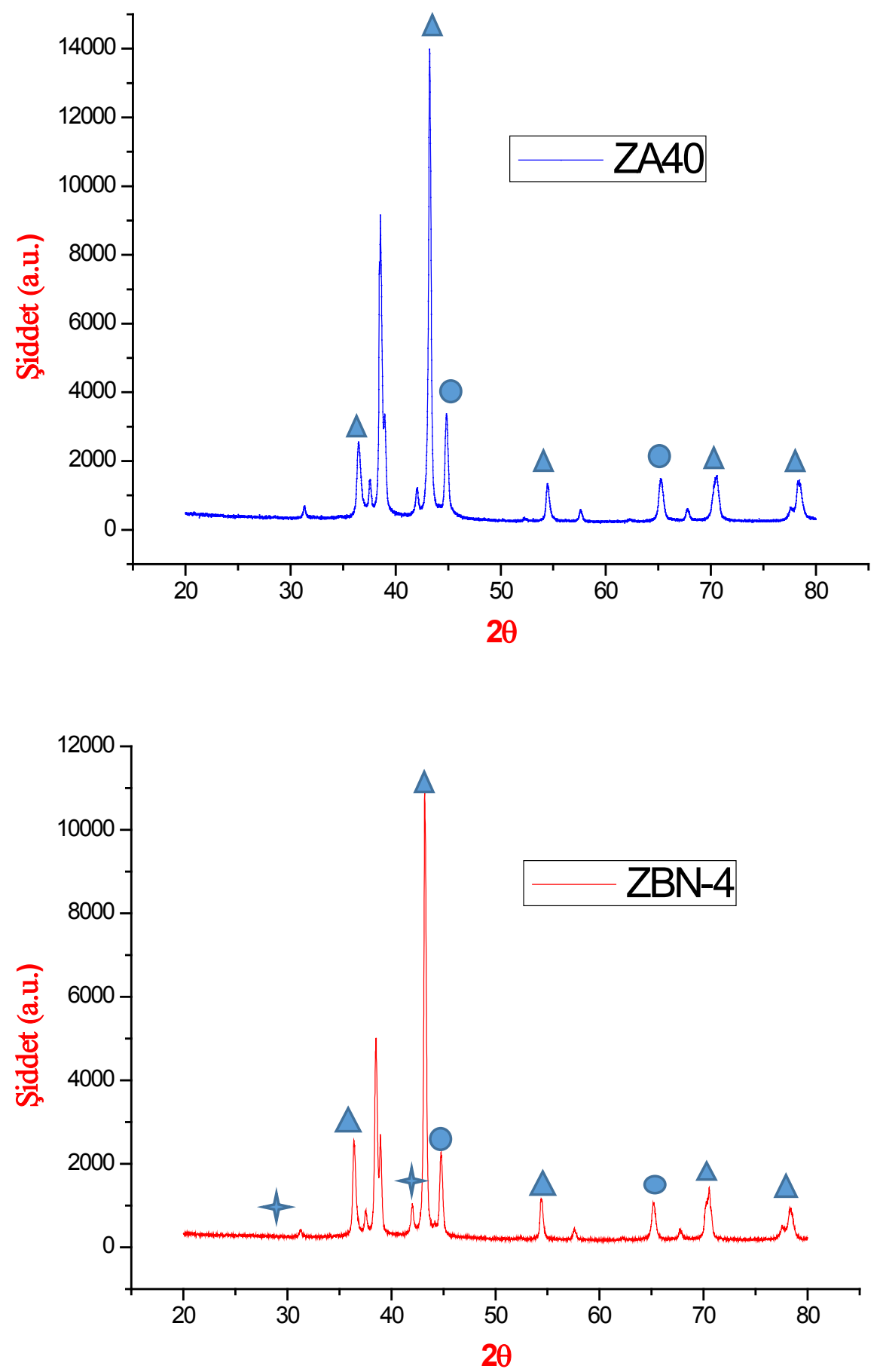

Şekil 4. ZA40 matris ve ZBN-4 kompoziti XRD analizleri $(\Delta: \mathrm{Zn}, \mathrm{O}: \mathrm{Al}, \uparrow: \mathrm{h}-\mathrm{BN})$

\subsection{Porozite ve Sertlik}

Tablo 3 ve şekil 5 incelendiği zaman h-BN takviyesinin artmasıyla matris ile kompozitler arasındaki porozite önemli ölçüde artış göstermiştir. En yüksek porozite değeri \%13,07 ile ZBN-4 numunesinde görülmüştür. ZA40 matriste porozite \%5,79 olarak ölçülürken ZBN-1 numunesinde hemen \%6,99 a yükselmiş olup ZBN-1 numunesi kompozitler içerisinde daha az agglemerasyona sahip olduğu düşünülmektedir. Burada paketlenme faktörünün etkisi ve tozların tane sınırlarına 
topaklanması ile tane sınırlarının büyümesi poroziteyi artırmıştır. Takviye miktarının artması ile yoğunluklar azalmıştır. Hot pres tekniğinin numunelerin yoğunlukları azaltıp poroziteleri artırdığı belirlenmiştir.

Tablo 3 ve şekil 6'da numunelerin Brinell sertlik değerleri gösterilmiştir. Matris malzemesinde sertlik değeri 122 HB ölçülürken h-BN miktarı artmasıyla en yüksek sertlik değeri 141 HB ile ZBN4 numunesinde ölçülmüştür. En önemli artış miktarı ZBN-1 ile ZBN-2 arasında gerçekleşmiştir. Matris içerisine h-BN gibi sert parçacık katılması numunelerin sertliği lineer bir şekilde artmıştır. Ayrıca numunelerin aşınma direncini ve mekanik özelliklerini olumlu ölçüde iyileştirmiştir. 3 saatlik mekanik alaşımla süresinin sinterlemeyi kolaylaştırmış olduğu ve h-BN takviyesinin matris içerisinde dağılımı sertlik artışında önemli bir etken olduğu görülmüştür.

Tablo 3. ZA40 ve kompozitlerin porozite ve sertlik değerleri

\begin{tabular}{ccc}
\hline Numune Kod & Porozite (\%) & Sertlik Brinell (HB) \\
\hline ZA40 & 5,79 & 122 \\
ZBN-1 & 6,99 & 127 \\
ZBN-2 & 11,06 & 135 \\
ZBN-3 & 11,37 & 138 \\
ZBN-4 & 13,07 & 141 \\
\hline
\end{tabular}

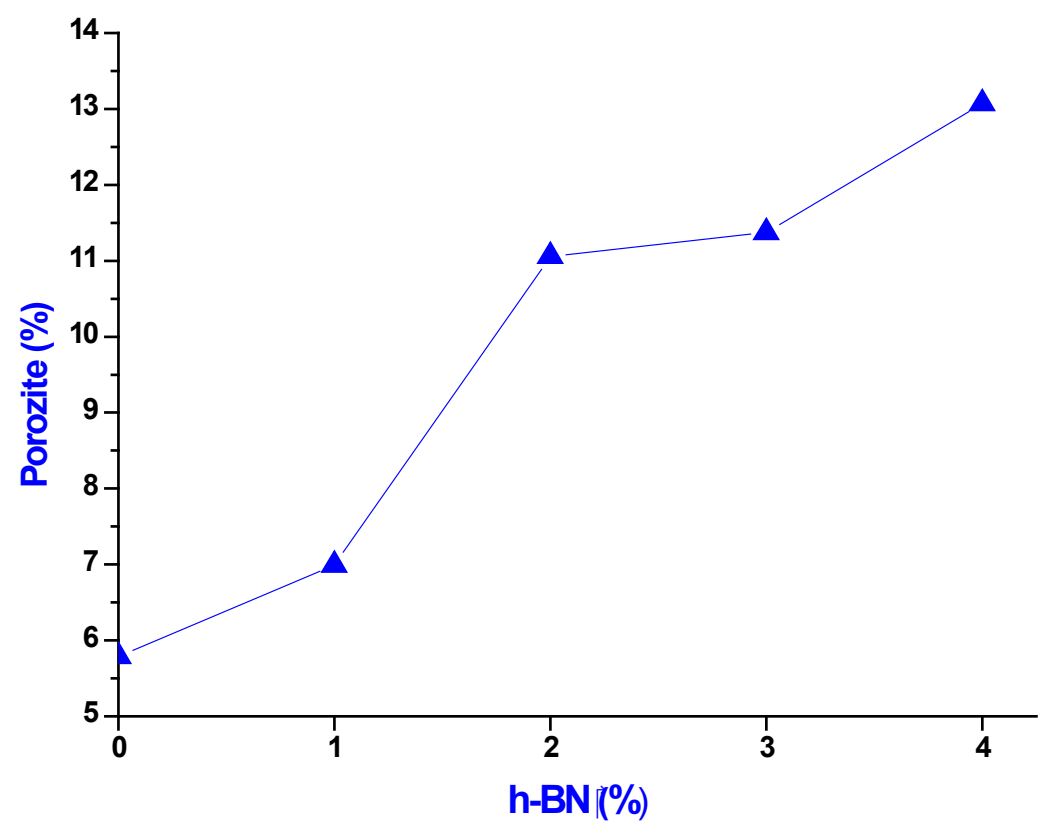

Şekil 5. ZA40 ve kompozitlerin porozite değerleri 


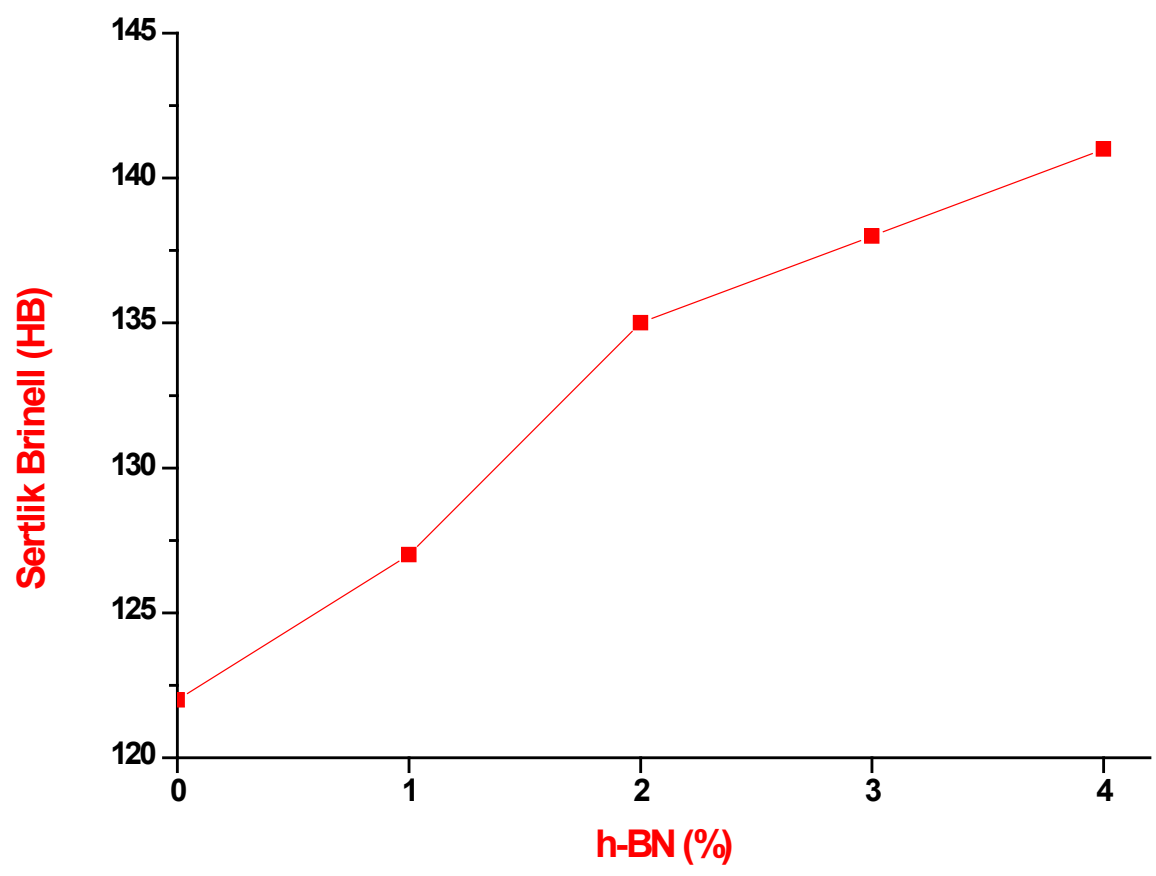

Şekil 6. ZA40 ve kompozitlerin sertlik değerleri

\subsection{Aşınma}

Aşınma verileri incelendiğinde Tablo 4’ ve şekil 7‘de $5 \mathrm{~N}$ yük altında matris malzemesinde 0,1357 mg olan ağırlık kaybı \% 1 oranında h-BN ilave edilmesiyle 0,1159 mg olarak ölçülmüştür. $\mathrm{Bu}$ durum matrise katılan sert parçacık takviyesi ile açıklanabilir. Buna sebep olarak ZA40 matrisi ile h-BN takviyesi arasında bağlanma dayanımında önemli bir artış görülmesi ile izah edilebilir. 10 $\mathrm{N}$ yük altında matris malzemesinin ağırlık kaybı 0,3229 mg iken artan h-BN takviyesi ile ağılık kayıpları azalmış olup \%4 h-BN takviyesi ile 0,1163 mg olarak ölçülmüştür. En az ağılık kaybı $5 \mathrm{~N}$ yük altında ZBN-4 numunesinde görülmüştür. Metal matrisli kompozitler için, en önemli faktörlerden biride takviye içeriğidir; çünkü mikroyapı takviye içeriği arttıkça (ağırlıkça \%) metalden seramik matrise dönüşmektedir (Savaşkan ve ark., 2004).

Tablo 4. ZA40 ve kompozitlerin porozite ve sertlik değerleri

\begin{tabular}{ccc}
\hline Numune Kod & 5N Ağılık Kaybı $(\mathrm{mg})$ & 10N Ağırlık Kayb1 $(\mathrm{mg})$ \\
\hline ZA40 & 0,1357 & 0,3229 \\
ZBN-1 & 0,1159 & 0,3051 \\
ZBN-2 & 0,0826 & 0,2776 \\
ZBN-3 & 0,0676 & 0,1606 \\
ZBN-4 & 0,0529 & 0,1163 \\
\hline
\end{tabular}




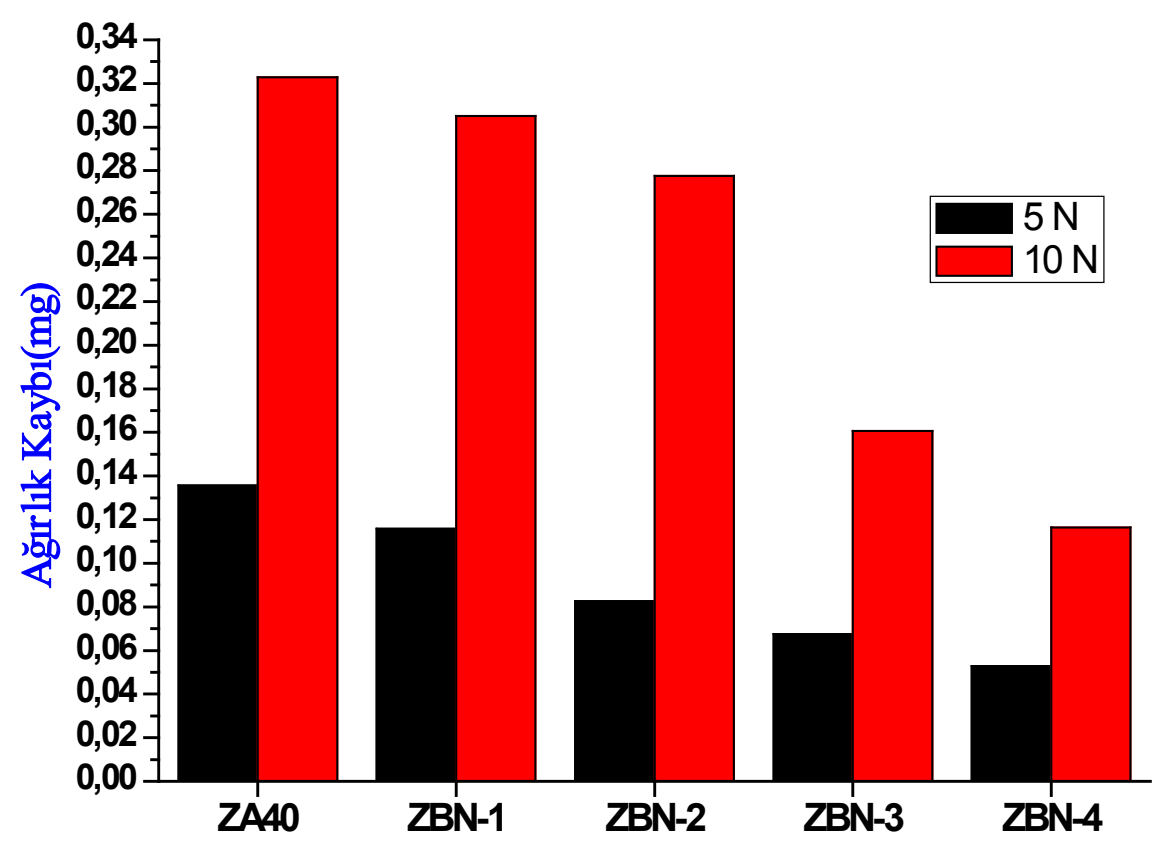

Şekil 7. ZA40 ve kompozitlerin farklı yüklerdeki ağırlık kayıpları

\subsection{Aşınma Yüzeyi İ́ncelenmesi}

Şekil 8'de aşınma yüzeyleri incelendiğinde ZA40/h-BN kompozitlerde adhesif ve abrasif aşınması olduğu SEM resimlerinde görülmüştür.

Kayma gerilmeleri, metal matris kompozitler için aşınma testi sırasında temas bölgesinin altındaki malzemeye aktarılır. Yüzey alanındaki yüksek deformasyon ve aşınma nedeniyle aşınma parçacıkları oluşur. İki kayan yüzey arasında mekanik olarak bir tabaka elde edilir. ZA40/h-BN kompozitlerinin aşınma testi sırasında iç yüzeyinde ince takviye parçacıkları bulunan yüzeyde plastik sertleşme matris fazı oluşur. Kırılgan bölge, delaminasyon işlemi sırasında matristen kopar. Matris içindeki takviye parçacıklarının varlığı, homojen dağılımı ile mikro alanlardaki mekanik gücünü artırır. (Yalçın ve ark., 2019) 


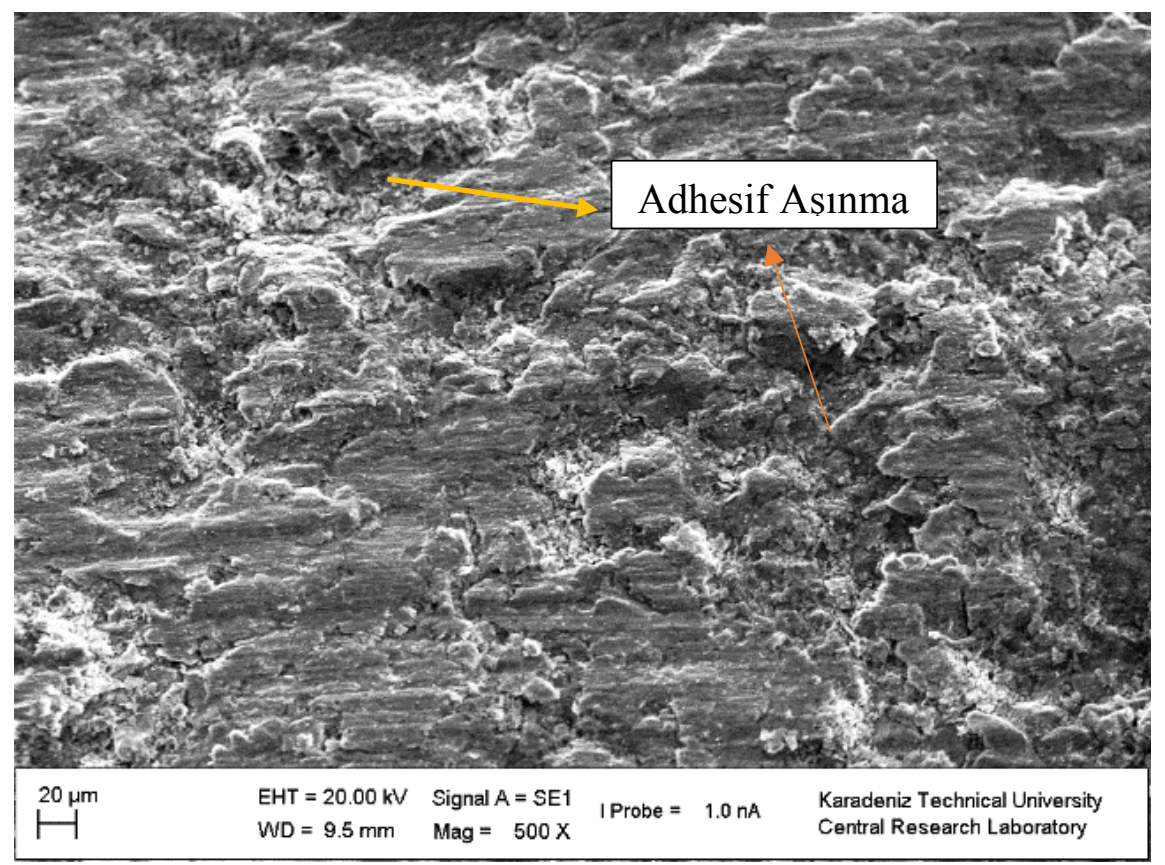

(a)

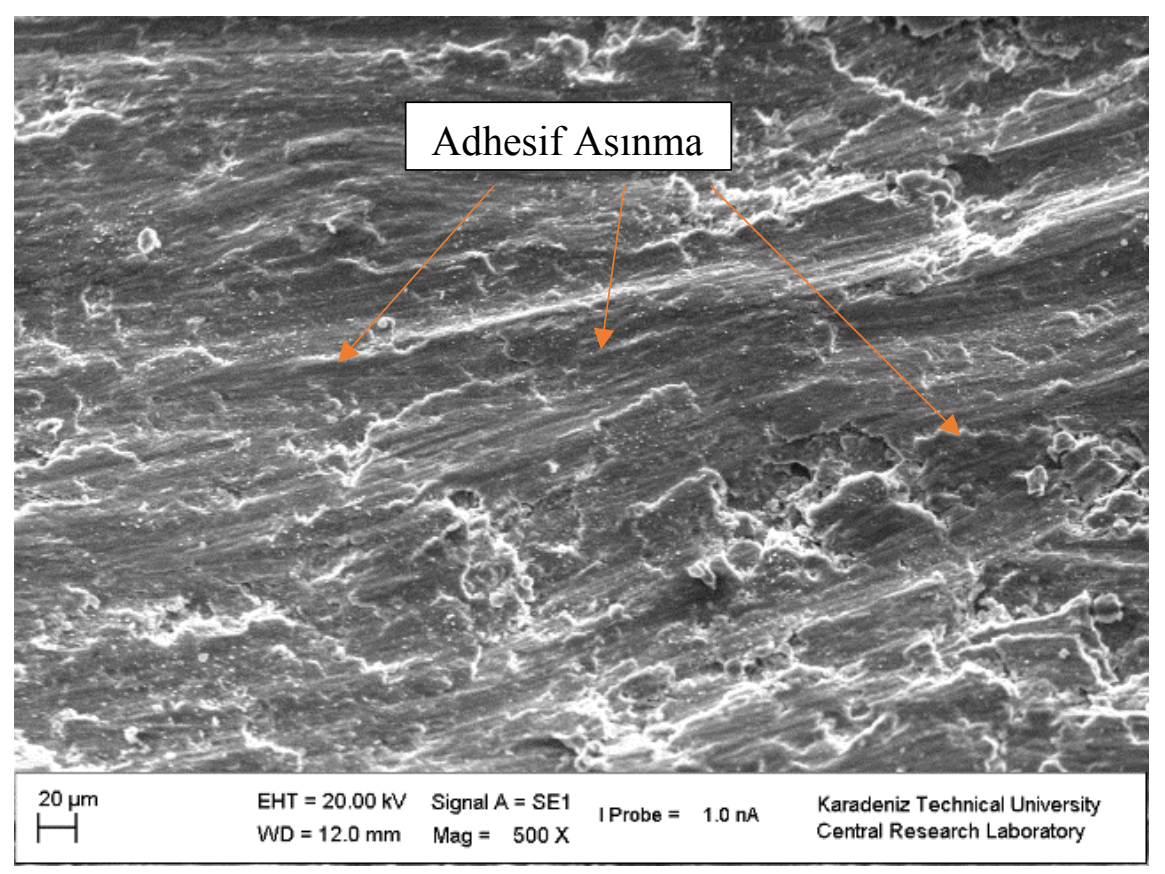

(b) 


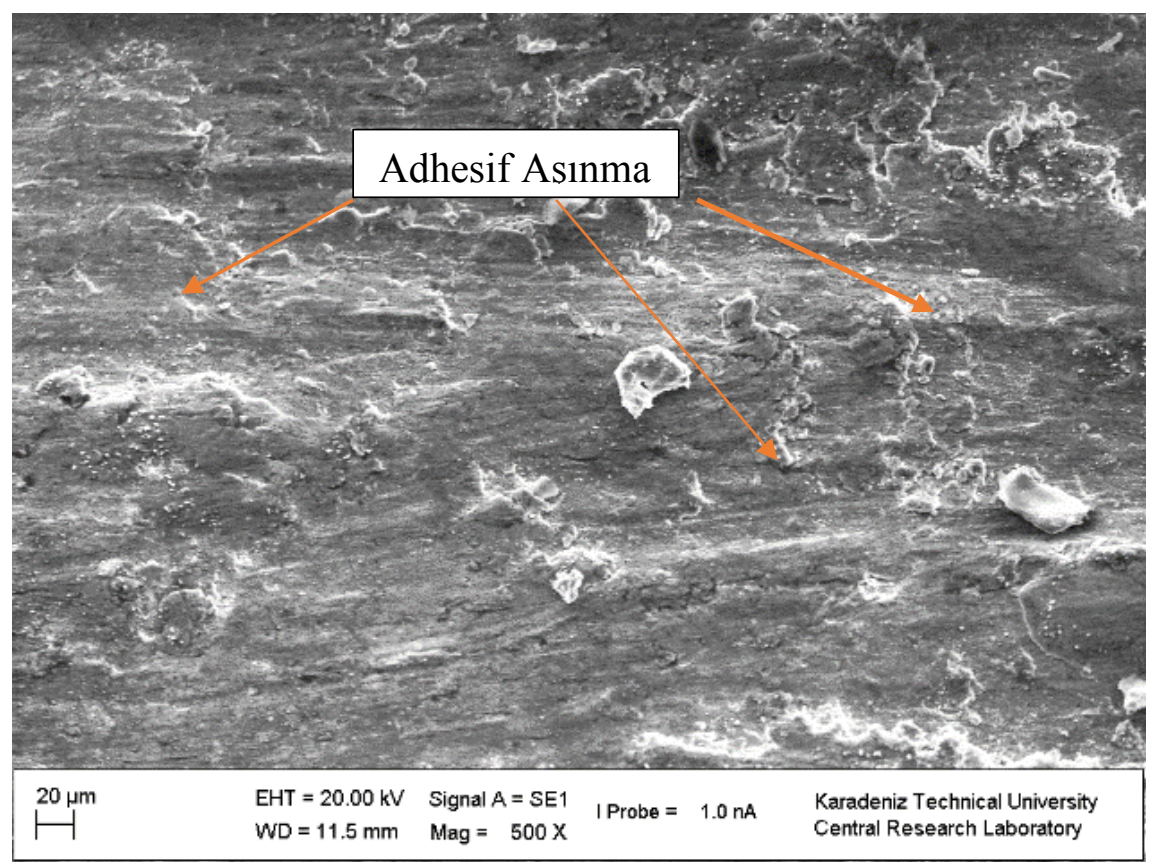

(c)

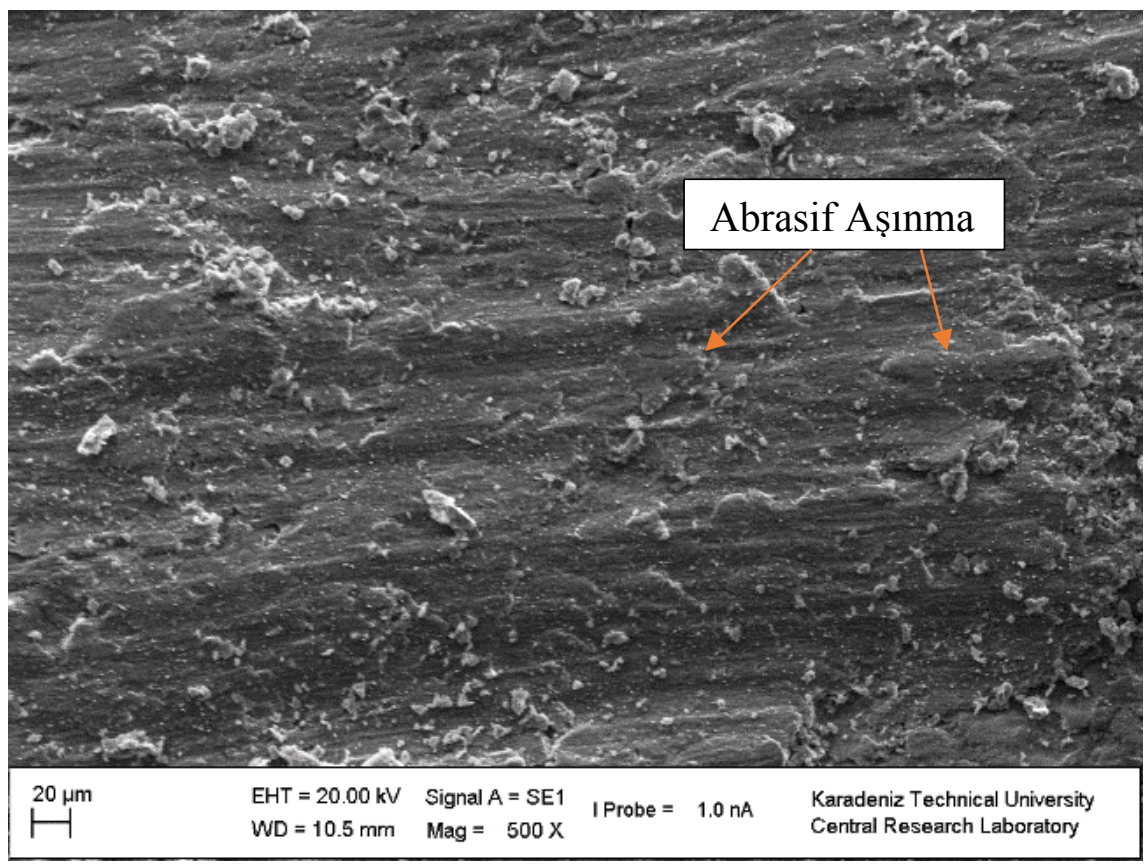

(d) 


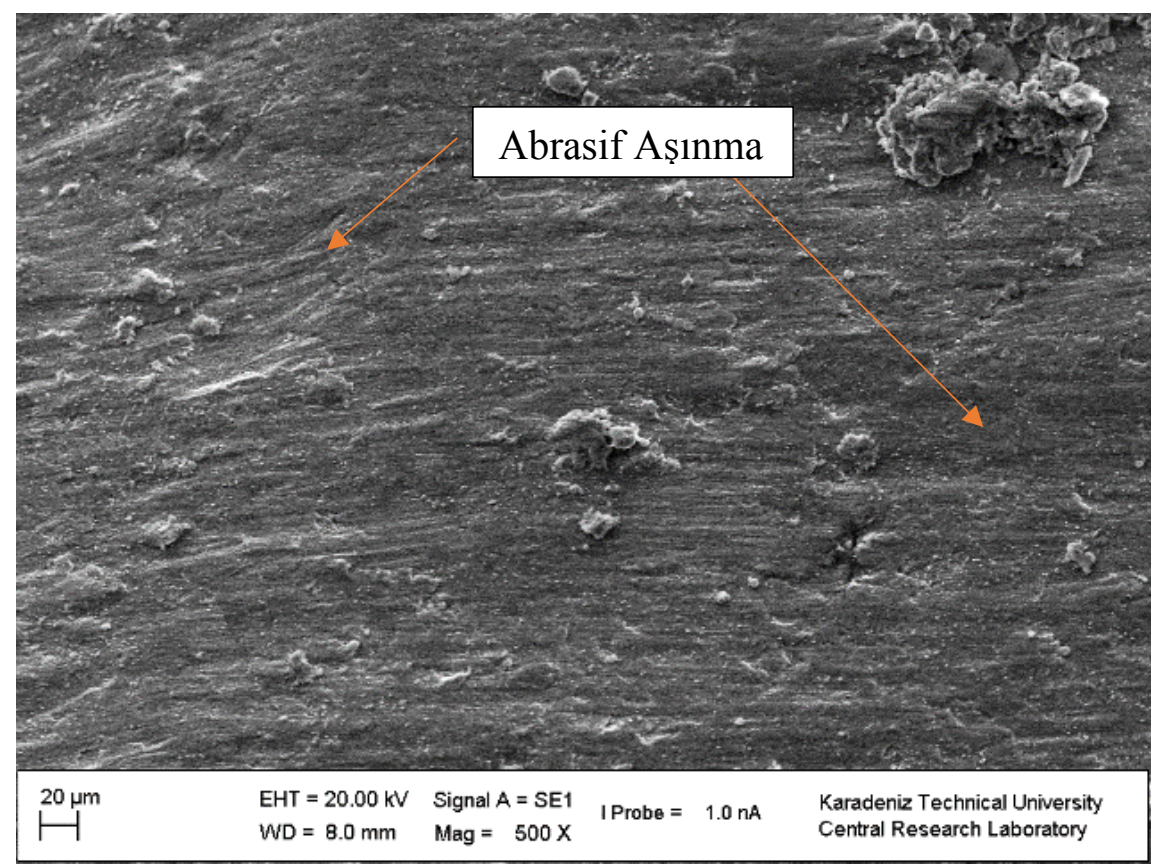

(e)

Şekil 8. 250 rpm devirde $10 \mathrm{~N}$ yük altında aşınma yüzeyleri SEM görüntüleri; (a) ZA40, (b) ZBN-1, (c) ZBN-2, (d) ZBN-3 ve (e) ZBN-4

Şekil 8-e 'de daha az bir aşınma olduğu göze çarpmaktadır. Burada esas olarak sert h-BN parçacıkların aşınma mekanizmasını abrasif aşınmaya döndürdüğünü özelliklede $10 \mathrm{~N}$ yük altında bunun daha belirgin bir şekilde görüldüğü belirlenmiştir.

\section{Sonuçlar ve Öneriler}

Bu çalışma kapsamında ZA40 matris malzemesi h-BN ile takviye edilerek kompozit numuneler toz metalürjisi yöntemi kullanılarak üretilmiştir. Üretilen numunelerde; yoğunluk, sertlik, mikroyapı ve aşınma davranışları incelenmiştir. Çalışmalar sonucu elde edilen sonuçlar aşağıda verilmiştir.

1) ZA40 matrisli h-BN takviyeli kompozit malzemeler mekanik alaşımlama ve sıcak presleme (hot pres) yöntemiyle üretildi.

2) ZA40/h-BN, kompozit tozlarının mekanik alaşımlama sonrası elde edilen mikroyapılarının karakterizasyon sonuçlarına göre; h-BN partiküllerinin ZA40 matrisi içerisinde ideal bir şekilde dağıtıldığı öğ̈̈tme süresi 3 saat olarak belirlenmiştir.

3) ZA40/h-BN kompozitlerin yoğunluk değerleri artan takviye oranları ile azalmış olup bununla birlikte porozite miktarı artmıştır.

4) ZA40/h-BN kompozitlerin sertlik değerleri artan takviye oranları ile artmış olup en yüksek sertlik değeri $141 \mathrm{HB}$ değeri ile ZBN-4 numunesinde, en düşük sertlik değeri de 122 HB ile matris malzemesi ZA40 ‘da ölçülmüştür. 
5) XRD analizlerinde h-BN pikleri açık bir şekilde görülmüştür.

6) Bütün kompozit malzemeler için ball-on-disk aşınma deneyi sonucunda gözlemlenen aşınma mekanizmaları adhesif ve abrasif aşınması olduğu belirlenmiştir. Aşınma kayıpları artan yük ile artmaktadır. En büyük ağırlık kayıpları $10 \mathrm{~N}$ yük altında meydana gelen aşınma deneylerinde görülmüştür. En yüksek ağırlık kaybı; ZA40 matris malzemesinde $10 \mathrm{~N}$ yük altında 0,3229 mg. olarak ölçülmüştür. En düşük ağırlık kaybı ise ZBN-4 numunesinde $5 \mathrm{~N}$ yük altında 0,0529 mg. olarak ölçülmüştür.

7) Bütün kompozitler ZA40 matris alaşımından daha yüksek bir aşınma direnci göstermiştir.

$\mathrm{Bu}$ çalışma kapsamında elde ettiğimiz sonuçlardan çıkartacağımız öneriler aşağıda belirtilmiştir.

1) Aşınma deneylerinde farklı hızlar, farklı yükler, farklı süreler altında ve daha uzun yol mesafesi uygulanarak aşınma davranışları daha geniş bir şekilde incelenebilir.

2) Kuru sürtünme ortamda yapılan aşınma deneyleri, tam yağlı ortam, kesikli yağlı ortamda da yapılarak malzemelerin aşınma davranışları değişik açılardan incelenebilir.

3) Üretilen numunelere çeşitli 1 sıl işlem uygulaması yapılarak mekanik özellikleri tekrar incelenebilir.

\section{Yazarların Katkısı}

Tüm yazarlar çalışmaya eşit katkıda bulunmuştur.

\section{Çıkar Çatışması Beyanı}

Yazarlar arasında herhangi bir çıkar çatışması bulunmamaktadır.

\section{Araştırma ve Yayın Etiği Beyanı}

Yapılan çalışmada araştırma ve yayın etiğine uyulmuştur.

\section{Kaynaklar}

Dama K., Prashanth L., Madeva N., Mathapati R., Mb. H. (2017). Microstructure and Mechanical Behavior of $\mathrm{B}_{4} \mathrm{C}$ Particles Reinforced ZA27 Alloy Composites, Materials Today Proceeding 7546-7553.

Hsu C-I., Wang G-L. L. Ger M-D., Hou K-H., (2016). Corrosion Behaviour of Electroless Deposited Ni$\mathrm{P} / \mathrm{BN}(\mathrm{h})$ Composite Coating. Int. J. , Electrochemical. Science 11, 4352-61.

Hsu C-II., Hou K-H., Ger M-D., Wang G-L. L., (2015). The effect of incorporated self-lubricated BN(h) particles on the tribological properties of Ni-P/BN(h) composite coatings, Applied. Surface. Science, $357,1727-35$,. 
Kumar N. S. (2018). Mechanical and Wear Behavior of ZA-27/Sic/Gr Hybrid Metal Matrix Composites. Materials Today: Proceedings, (5), 19969-19975.

Li, M., Lu, S., Long, F. et al. (2015). Effect of Y Addition on the Mechanical Properties and Microstructure of Zn-Al Alloys. JOM 67, 922-928.

Savaskan, T., Hekimoglu, A.P., Purcek, G., (2004). Effect of copper content on the mechanical and sliding wear properties of monotectoid-based zinc-aluminium-copper alloys. Tribology International 37, 4550 .

Smith, W., (1993). Structures and properties of engineering alloys. (2nd ed.) New York, , McGraw Hill,

Ranganath G, Sharma SC, Krishna M. (2001) "Dry sliding wear of garnet reinforced zinc/aluminium metal matrix composites". Wear; (251),1408-1413.

Yalçın, E. D. (2018). ZA27/Grafen/B ${ }_{4}$ C Nanokompozitlerin Toz Metalurjisi Yöntemi ile Üretilmesi ve Özelliklerinin İncelenmesi. Doktora Tezi, Karadeniz Teknik Üniversitesi, Fen Bilimleri Enstitüsü, Trabzon

Yalçın E. D. , Çanakçı A. , Erdemir F. , Çuvalcı H. , Karabacak A. H. (2019). Enhancement of Wear and Corrosion Resistance of ZA27/Nanographene Composites Produced by Powder Metallurgy. Arabian Journal for Science and Engineering. 44, 1437-1445.

Yalçın E. D. (2021, Nisan). Wear Properties of ZA40/Ni Alloy Composites International Congress of Academic Research-(ICAR), (s. 91-96). Ankara.

Yalçın E. D., Çanakçı A., (2021, Temmuz). Hegzegonal Bor Nitrür Katkılı ZA40 Alaşımının Aşınma Parametrelerinin İncelenmesi, UBCAK6, (s.91-96) Ankara. 